\title{
Concepções sobre Interdisciplinaridade entre Arte e Ciências: estudo a partir do relato de um professor e de alunos da Educação Básica
}

\section{Conceptions about Interdisciplinarity between Art and Science: a study of the report by a teacher and students in Basic Education}

\author{
Marco Antonio João Fernandes Junior ${ }^{1}$ \\ João José Caluzi² \\ ${ }^{1}$ Faculdades Integradas Regionais de Avaré (FIRA), Avaré, SP, Brasil. \\ Autor correspondente: prof.marco@fira.edu.br \\ ${ }^{2}$ Universidade Estadual Paulista (UNESP), Faculdade de Ciências (FC), Bauru, SP, Brasil.
}

Resumo: O presente artigo tem por objetivo apresentar as concepções de um professor de ciências, bem como de um grupo formado por alunos do $9^{\circ}$ ano do Ensino Fundamental de uma escola pública do interior do Estado de São Paulo, sobre a interdisciplinaridade entre arte e ciências. Em atividades de ensino e pesquisa, foi solicitado aos alunos que respondessem como percebem a relação da disciplina arte com as outras, mais especificamente com as ciências. Para a coleta de dados foram utilizadas entrevistas e questionários semiestruturados, cujo conteúdo foi analisado a partir da proposta de Bardin. Nas respostas do professor e dos alunos, observou-se a necessidade de práticas interdisciplinares para ampliar e desconstruir conhecimentos equivocados que ambos possuem em relação à arte e à ciência.

Palavras-chave: Interdisciplinaridade da educação; Ensino de arte; Ensino de ciências; Educação básica.

\begin{abstract}
The present article aims at presenting the conceptions of a science teacher, as well as of a group of 33 students in the $9^{\text {th }}$ grade of Fundamental Education in a public school of São Paulo state, about the interdisciplinarity between Art and Science. In both teaching and research activities, students were required to answer how they see the correlation of Art with other school subjects, more specifically Science. For the collection of data, interviews and semi-structured questionnaires were used, and the material was analyzed according to Bardin's proposal. In the answers provided by the teacher and the students, the need has been detected for interdisciplinary practices to expand and deconstruct mistaken knowledge that they have regarding Art and Science.
\end{abstract}

Keywords: Interdisciplinarity in education; Art teaching; Science teaching; Basic education.

Recebido em: 26/02/2020

Aprovado em: 13/04/2020 


\section{Introdução}

A necessidade de aproximar arte e ciências não está atrelada apenas à elucidação de conteúdos científicos, mas também humanísticos, pois para se criar uma concepção de educação significativa para o aluno, a qual transcenda os muros da escola, é necessário que o conhecimento científico vá além de uma simples aprendizagem de leis e teorias. É necessário considerar a emoção, a criatividade e a imaginação ligadas à racionalidade como peças fundamentais para a formação de indivíduos conscientes de seus papéis como cidadãos (LUCISANO; NEVES, 2010).

As propostas metodológicas que orientam o ensino de ciências e de arte na educação básica têm passado por diversas transformações, e, na atualidade, encontram-se em maior evidência a metodologia investigativa em ciências (SÃO PAULO, 2010a) e a abordagem triangular em arte (SÃO PAULO, 2010b). Ambas as propostas centralizam o aluno no processo de ensino e aprendizagem, valorizando o seu repertório cultural e dando-lhe voz para ser um aluno questionador e a não aceitar a "verdade" como lhe é imposta. Em outras palavras, o professor não age como um transmissor de conhecimento, mas como um propositor. Como dizia Paulo Freire (FREIRE, 1996, p. 47): "[...] ensinar não é transferir conhecimento, mas criar as possibilidades para sua própria produção ou sua construção".

Criar possibilidades para a construção do conhecimento é uma tarefa árdua, pois ela abrange uma série de fatores, entre eles, Silva e Neves (2015) destacam que a crise que envolve a educação brasileira é ocasionada pela rapidez com que os desafios se colocam pela imposição da tecnologia, principalmente da informática, pois esta tem alterado a organização social, o poder político e a cultura, com fortes reflexos na educação. Logo, um ensino fragmentado em disciplinas, produz uma visão descontextualizada da sociedade e da vida cotidiana, podendo ser superada pela defesa de Fazenda (1994, p.14), segundo a qual a "[...] interdisciplinaridade facilitaria o enfrentamento dessa crise do conhecimento".

Uma prática educativa interdisciplinar consiste na iniciativa de incitar o diálogo com outras formas de conhecimentos que não estamos habituados, por isso exigem do educador autoconhecimento, humildade, coerência, expectativa e audácia (FAZENDA, 1994). Dessa forma, considerando a velocidade com que a informação na atualidade é disseminada, não basta ter apenas o domínio do conteúdo de uma determinada disciplina, é necessário pensálo de forma crítica e relacioná-lo com outras estruturas de conhecimento, superando, assim, a visão unilateral da realidade e reconhecendo múltiplas formas de olhar e analisar uma mesma situação (PILLAR, 2011).

Ante o exposto, o estudo que aqui se apresenta é parte de uma pesquisa mais ampla, realizada no Programa de Pós-graduação em Docência para Educação Básica, da Universidade Estadual Paulista Júlio de Mesquita Filho (UNESP), do câmpus de Bauru, o qual partiu do seguinte questionamento: como os alunos percebem a relação da arte com as outras disciplinas, mais especificamente com as ciências?

Nessa perspectiva, o artigo tem por objetivo apresentar as concepções dos alunos e do professor de ciências a respeito da interdisciplinaridade entre arte e ciências. 


\section{Arte e Ciências: questões}

Preliminarmente, as relações entre a arte e as ciências foram esboçadas por Zamboni (2001) a partir de sua interpretação da obra A estrutura das revoluções científicas, de Thomas Kuhn (KUHN, 2011). Para Zamboni (2001), a teoria elabora por Kuhn toma como base as mudanças ocorridas nas ciências, mas guardadas as suas especificidades, ocorrem mecanismos semelhantes na arte.

Dessa forma, tal como observou Atalay (2009, p. 117), o que difere o trabalho do artista daquele praticado pelo cientista são seus enfoques: "[...] o artista se interessa em interpretar o mudo visível; o cientista, em explicar como e por que age a natureza". Permite, desse modo, que se entenda arte e ciências como atividades humanas que, na maioria das vezes, divergem em suas produções. Geralmente, a ciência parte das necessidades externas, enquanto a arte exterioriza as particularidades do olhar do artista.

Embora as definições e as implicações da arte e da ciência possuam uma dimensão abrangente e complexa, é importante pensar arte e ciências com caráter social. Tratar as áreas dos saberes sob a ótica cultural é reforçar o caráter humano dessas atividades (BENEDICTO, 2018).

Conforme estudado por Benedicto (2018), os conceitos de arte e ciências podem ser associados a diferentes vertentes, entre elas: a epistemológica, que trata arte e ciências como áreas especializadas do conhecimento; e a pedagógica, na qual o termo se refere à organização curricular, tratando arte e ciências como disciplinas que compõem a educação básica.

Ainda para Benedicto (2018), no contexto pedagógico, a ideia de disciplina apresentase associada à noção de fragmentação e especialização do conhecimento e, a partir disso, emergiu o debate sobre a teoria da interdisciplinaridade, cujo intuito é a superação das barreiras disciplinares e a evidenciação das correspondências entre todas as áreas do saber.

\section{Procedimentos Metodológicos}

Como já mencionado, o estudo corresponde a uma pesquisa mais ampla (FERNANDES JUNIOR, 2017), por isso optou-se aqui por um recorte para atender ao objetivo do artigo, ou seja, divulgar as concepções de um professor e de seus alunos sobre a interdisciplinaridade entre arte e ciências.

A coleta de dados para a pesquisa ocorreu durante o ano de 2015, em uma escola pública do interior do estado de São Paulo, no município de Taguaí. Os sujeitos envolvidos foram um professor de ciências e 33 alunos do $9^{\circ}$ ano do Ensino Fundamental.

É válido destacar que um dos pesquisadores foi professor da disciplina de arte na respectiva escola e da turma dos discentes colaboradores, por isso o desenvolvimento da pesquisa ocorreu pela ótica da metodologia da pesquisa-ação, tendo como principal referência Michel Thiollent (THIOLLENT, 2009, p. 17). Para ele, "[...] na pesquisa-ação os pesquisadores desempenham um papel ativo no equacionamento dos problemas encontrados, no acompanhamento e na avaliação das ações desencadeadas em funções dos problemas". 
Nesse sentido, a pesquisa e o tratamento dos dados obedeceram a uma abordagem qualitativa, para a qual foram utilizados, como instrumentos para coleta de dados, entrevistas com o professor de ciências e questionários semiestruturados com os alunos. Conforme esclarecem Alves e Silva (1992), a entrevista possui uma estrutura que abrange a necessidade de obter dados dentro de um contexto em que são definidos os interesses do pesquisador, que têm vinculação direta com os pressupostos teóricos e contatos prévios com a realidade sob estudo, garantindo a adequação do roteiro da aplicação da pesquisa à realidade dos sujeitos, bem como permitindo, durante a entrevista, elaborar e reelaborar novas questões que tornem as respostas mais completas.

A pesquisa em questão teve início no primeiro semestre de 2015, a partir da entrevista gravada com o professor de ciências. Essa entrevista teve por finalidade elencar as metodologias adotadas pelo professor de ciências para desenvolver seu trabalho e sua compreensão a respeito de interdisciplinaridade, arte e ciências.

Sendo assim, a partir da entrevista e das questões expostas pelo referido professor foi possível elaborar o Quadro 1.

Quadro 1 - Questões utilizadas na entrevista com o professor de ciências

\begin{tabular}{|l|l|}
\hline N. questão & \multicolumn{1}{|c|}{ Perguntas } \\
\hline P1 & Quais metodologias e recursos materiais costuma adotar para desenvolver seu trabalho? \\
\hline P2 & Já realizou uma parceria com algum professor para desenvolver ou aprofundar algum conteúdo? \\
\hline P3 & O que você entende por interdisciplinaridade? \\
\hline P4 & As ciências podem ser entendidas como cultura? \\
\hline P5 & O que você acredita que uma pessoa deve saber para ser considerada cientista? \\
\hline P6 & O que você acredita que uma pessoa deve saber para ser considerada artista? \\
\hline P7 & $\begin{array}{l}\text { Você acredita que o artista (desenhista/pintor) ou o conhecimento artístico contribuiu para o } \\
\text { desenvolvimento das ciências? }\end{array}$ \\
\hline P8 & \begin{tabular}{l} 
A imagem é importante para as ciências? Justifique sua resposta. \\
\hline P9
\end{tabular} \\
\hline
\end{tabular}

Fonte: elaborado pelos autores.

As questões que compuseram o Quadro 1, alinhadas ao objetivo do estudo, direcionaram a organização dos questionários semiestruturados utilizados para coletar as respostas dos alunos (Quadro 2), que teve por finalidade elencar as concepções dos alunos sobre arte; a disciplina de arte e a interdisciplinaridade entre arte e ciências. O questionário foi aplicado no segundo semestre de 2015.

Para os questionários utilizados com os alunos, foi realizado um pré-teste no primeiro semestre de 2015, com uma turma de $9^{\circ}$ ano que não participou da pesquisa. $O$ objetivo deste pré-teste foi verificar se as questões estavam objetivas e de fácil entendimento para os alunos. 
Quadro 2 - Lista de perguntas utilizadas no questionário com os alunos

\begin{tabular}{|c|c|}
\hline N. questão & Perguntas \\
\hline P1 & Para você, o que é arte? \\
\hline P2 & Você acha que a aula de arte é importante? Por quê? \\
\hline P3 & Você gosta da aula de arte? Justifique. \\
\hline P4 & $\begin{array}{l}\text { O conteúdo que você aprende nas aulas de arte tem alguma relação com os que você estuda nas outras } \\
\text { disciplinas? }\end{array}$ \\
\hline P5 & Você acha que é possível aprender arte estudando ciências, ou aprender ciências estudando arte? Justifique. \\
\hline P6 & O que você acredita que uma pessoa deve saber para ser considerada artista? \\
\hline P7 & O que você acredita que uma pessoa deve saber para ser considerada cientista? \\
\hline P8 & A imagem é importante para a ciência? Justifique sua resposta. \\
\hline P9 & Será que o artista ou o conhecimento artístico contribuiu para o desenvolvimento da ciência?. \\
\hline
\end{tabular}

Fonte: elaborado pelos autores.

Os dados coletados foram interpretados considerando as fases da análise de conteúdo propostas por Bardin (1977, p. 95), organizadas em: "1. pré-análise; 2. exploração do material; 3. tratamento dos resultados, inferência e interpretação."

A pré-análise ocorreu pela leitura fluente dos dados coletados - entrevista com o professor de ciências e os questionários aplicados aos alunos -, objetivando identificar as concepções gerais de arte, ciências e interdisciplinaridade dos sujeitos envolvidos na pesquisa.

A exploração do material coletado se deu pela organização e categorização de palavras frequentes (BARDIN, 1977), ou seja, foi possível identificar nas respostas do professor de ciências e dos alunos, palavras que permitiram agrupá-las conforme o significado e o contexto em que os sujeitos as utilizaram. Para Bardin (1977), a regularidade quantitativa de aparição de palavras associadas ao tema (assunto que se investiga) permite considerá-lo significativo para a interpretação.

Dessa forma, o tratamento dos resultados estabeleceu a categorização e a contagem de frequência das palavras-tema, permitindo a interpretação do conteúdo manifesto e latente nas respostas do professor de ciências e dos alunos.

Pela forma como os dados foram tratados, o número de perguntas que compõem o questionário ficou superior ao número de gráficos (apresentados mais adiante) elaborados para apresentar os resultados. Para reunir as concepções dos alunos sobre um determinado assunto, mais de uma pergunta do questionário foi levada em consideração; e por serem questões abertas, a resposta de um aluno também pode apresentar diversas categorias, o que influenciou nos números de respostas apresentadas nos gráficos. 


\section{Apresentação dos Resultados}

Nesta seção são expostas as respostas da entrevista realizada com o professor de ciências e as concepções dos alunos do $9^{\circ}$ ano do Ensino Fundamental.

\section{Da entrevista com o professor de ciências}

Quando questionado sobre quais abordagens metodológicas são utilizadas para desenvolver suas aulas, o professor de ciências mencionou que segue "na linha", ou seja, fidedignamente, o Material de Apoio ao Currículo do Estado de São Paulo (SÃO PAULO 2010a). Entretanto, destacou que o considera vago, necessitando de complementação, a qual se faz a partir da utilização de livros didáticos, de experimentos e tarefas para serem realizadas em casa pelos alunos, mas atenta que nem todos os alunos as realizam.

Sobre o trabalho em conjunto com outros professores, ele mencionou que realiza com o intuito de aprofundar determinados conteúdos sobre os quais não possui domínio e costuma se organizar com outros docentes em momentos oportunos, como no intervalo das aulas, ou no horário de atividades de trabalho pedagógico coletivo (ATPC). Afirmou ter feito muito disso na "época da interdisciplinaridade", compreendendo-a como "um trabalho mútuo entre as disciplinas".

Quanto ao que entende pela disciplina arte no currículo escolar, relembrou de atividades realizadas quando cursou a educação básica, atividades manuais e desprovidas de contextualização. Também comentou que a disciplina é importante por conteúdos associados a ela aparecerem nos exames vestibulares e a considera uma forma de conhecimento. Também revelou que o Material de Apoio ao Currículo do Estado de São Paulo (SÃO PAULO, 2014) contém imagens de obras de arte. Entretanto, não realiza a leitura, pois se considera leigo em arte. Por último, entende a ciência como cultura, por ela ser aplicada no cotidiano.

Quanto à distinção entre o cientista e o artista, mencionou que o primeiro deve ser muito curioso, estar bem informado e ter muito conhecimento; o artista deve possuir "dons" para desempenhar certos trabalhos como pintura, teatro etc.

Por fim, acredita que a arte contribui para o desenvolvimento da ciência. Tal como os experimentos servem para comprovar as teorias, as imagens e a arte podem ser utilizadas para concretizar determinados conteúdos entendidos como abstratos e as linguagens da arte podem ser relacionadas com os sentidos do corpo, podendo assim facilitar a aprendizagem.

Das respostas do professor, é possível inferir que possui uma visão tradicional de ensino. Para ele, as inovações teóricas na metodologia e didática de ensino são "modas", como afirma quando se refere à interdisciplinaridade. Possui uma visão estereotipada de ciência, arte, cientista e artista. Por exemplo, confunde arte com artesanato. A arte aparece associada a uma necessidade prática, no caso, para o vestibular. Assim, a arte não tem valor por si, mas somente associada com outra atividade. Ele também possui uma visão de senso comum de ciência: "os experimentos servem para comprovar teorias". 


\section{Dos questionários aplicados aos alunos do $9^{\circ}$ ano do ensino fundamental}

A análise das respostas dos discentes aos questionários foi interpretada a partir das fases de análise de conteúdo proposta de Bardin (1977), como já indicado na seção referente aos procedimentos metodológicos.

Sendo assim, a pré-análise revelou que determinadas palavras apareciam com frequência nos questionários de diferentes alunos. Dessa forma, buscou-se uma categorização a partir de palavras (tema) para poder entender as concepções dos discentes sobre arte e ciências. A categorização é exposta por meio de gráficos.

Quando questionados sobre o que entendiam por arte, o grupo expressou opiniões que se referiam à arte como manifestação artística, como também a disciplina de arte na educação básica (Gráfico 1).

Gráfico 1 - A concepção de arte dos alunos

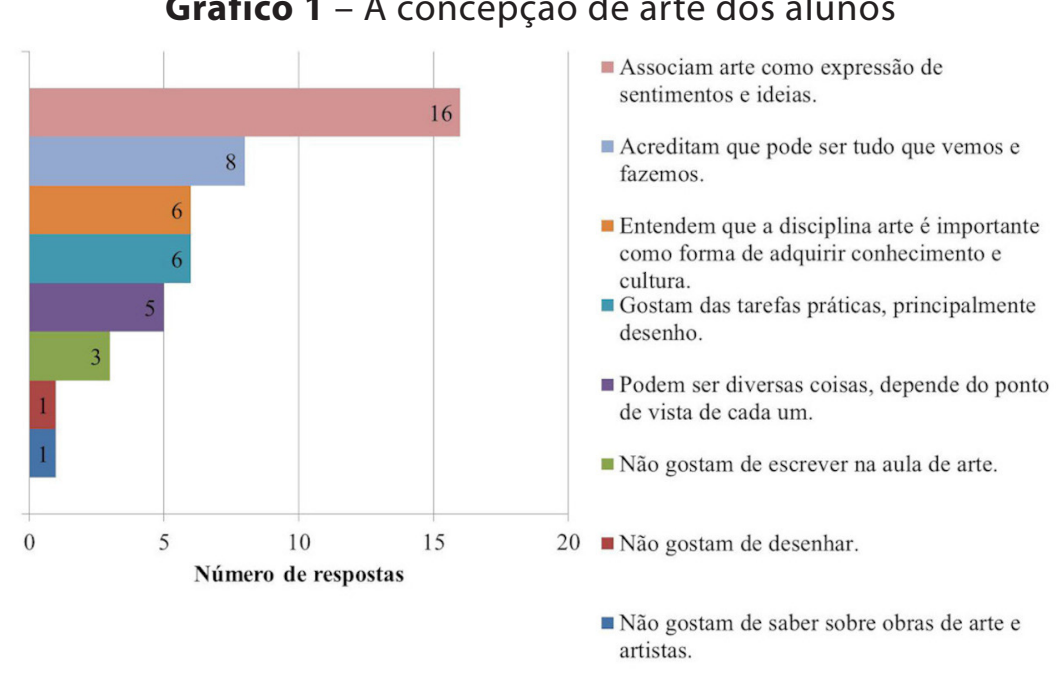

Fonte: elaborado pelos autores.

Predominantemente, constatou-se que os alunos associaram arte com a expressão de sentimentos e ideias (16), porém, nos questionários, não evidenciaram quais tipos sentimentos ou quais ideias especificamente estão atrelados à produção artística. Talvez por dificuldade e ausência de compreensão sobre os propósitos das produções artísticas, alguns alunos acreditam que arte pode ser tudo o que vemos ou fazemos (8), transparecendo, assim, uma produção sem critérios definidos, seja por uma tradição artística, ou pelo próprio artista, que também impõe limites ao seu trabalho. Por isso, é importante destacar que diante dos problemas para definir o que é arte, alguns alunos evidenciaram seu caráter subjetivo, o qual a faz ser diversamente conceituada, dependendo do ponto de vista de cada um (5).

Os alunos que responderam ao questionamento acreditam que a disciplina arte tem sua importância na escola, por oportunizar o conhecimento e o acesso às diferentes culturas (6). Considerou-se, assim, muito importante esse argumento, pois o ensino de arte tem a preocupação com a formação do alunado, oportunizando o acesso a obras, artistas, estilos e costumes, que seriam de difícil acesso sem o ensino de arte na educação básica. Conforme Barbosa (2016) é contraditório pensar que o ensino de arte seja dispensável e depois discriminar as manifestações artísticas que emergem das classes sociais mais populares, ou clamar por ampliação de plateia em teatros, museus, cinemas etc. 
Sobre a aula de arte, alguns alunos revelaram que gostam da disciplina, principalmente das tarefas práticas, como desenho (6), porém cabe a ressalva, que não apenas o desenho é utilizado como ferramenta para o ensino e aprendizagem da arte, mas sim, diferentes modalidades de expressão, as quais incluem as artes visuais, música, dança e teatro. Por outro lado, alguns discentes mencionaram que não gostam de escrever (3), desenhar (1) e saber sobre obras de artes e artistas (1).

O Gráfico 2, Relação da Arte com outras disciplinas, mostra a concepção interdisciplinar da arte para os alunos.

Gráfico 2 - Relação da Arte com as outras disciplinas

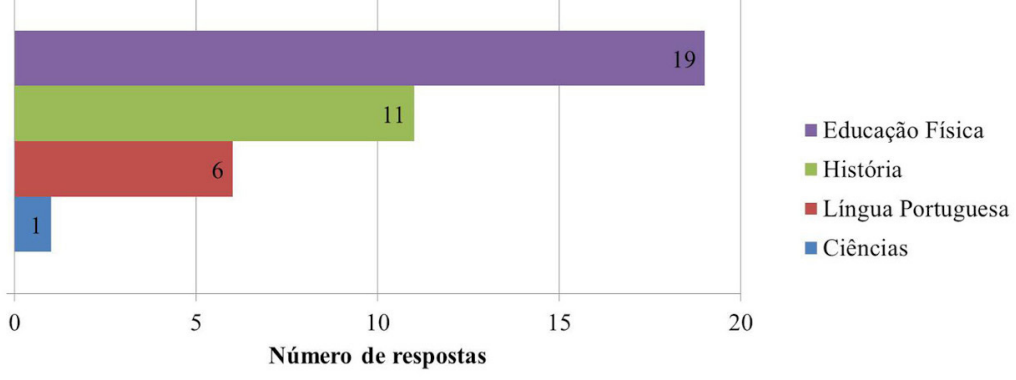

Fonte: elaborado pelos autores.

Como se pode observar, grande parte dos alunos mencionou a educação física (19) no questionário. A associação ficou evidente por conta dos estudos sobre a dança, que se encontram como conteúdo nas duas disciplinas.

A disciplina história apareceu associada à arte (11), por conta dos períodos e das pinturas históricas. Em língua portuguesa (6), o grupo mencionou o teatro e as figuras de linguagem, porém não as exemplificaram. Apenas um aluno relacionou arte com ciências (1) e sua justificativa foi a comparação da câmera fotográfica com o olho humano - Conteúdo do $3^{\circ}$ bimestre do material de apoio ao currículo para o ensino de Ciências (SÃO PAULO, 2014).

O Gráfico 3 delimita os questionamentos quanto à possível relação dos conteúdos da disciplina arte com ciências.

Gráfico 3 - Associação dos conteúdos de Arte com Ciências

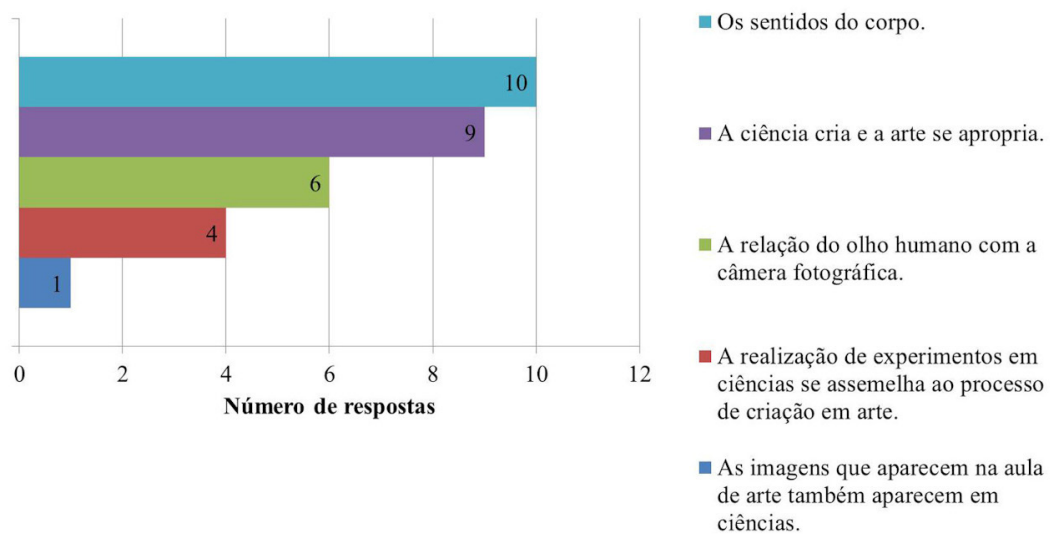

Fonte: elaborado pelos autores. 
O grupo enfatizou os sentidos do corpo (10) - Conteúdo do $3^{\circ}$ bimestre do material de apoio ao currículo para o ensino de ciências (SÃO PAULO, 2014), relacionando a visão com artes visuais, a audição com apreciação musical, o tato com a prática da pintura. Da mesma forma, justificaram que a arte se apropria das invenções científicas como a produção de tintas sintéticas (9). Do questionamento da relação dos conteúdos de arte com ciências surgiram associações da câmera fotográfica com o olho humano (6). Assim como a comparação da realização de experimentos na aula de ciências com as tarefas práticas na aula de arte (4). Houve também um relato, em que o aluno mencionou que no Caderno do Aluno - Material de Apoio ao Currículo do Estado de São Paulo (SÃO PAULO, 2014) -, contém imagens de obras de arte (fato também comentado pelo professor de ciências na entrevista).

Além dos questionamentos sobre arte e ciências, os discentes também responderam sobre o que pensavam que uma pessoa deveria saber para ser considerada artista (Gráfico 4).

Gráfico 4 - Qualidades de uma pessoa para ser artista

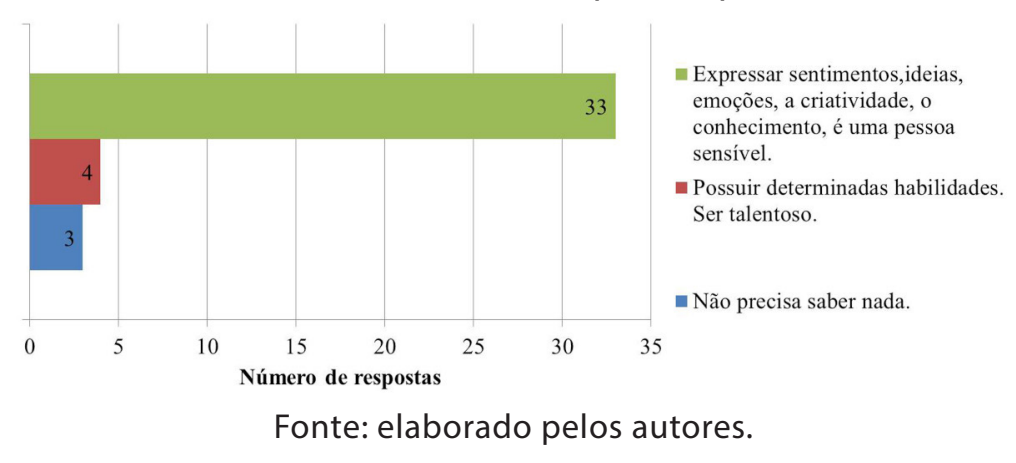

Em maior número, os alunos responderam que para ser um artista é preciso saber expressar sentimentos através da obra (33), Por exemplo: "uma pessoa que esteja triste faz uma pintura e todos entendem os seus sentimentos, ela, para mim, pode ser um artista" (Resposta de aluno).

Uma pequena parcela dos alunos acrescentou em suas repostas que, além de sentimentos, o artista deve expressar ideias, ser uma pessoa sensível e ter conhecimento. Aparentemente, o conhecimento para ser artista está associado a habilidades manuais e gestuais (4), como ocorre na prática da pintura, da dança, da música etc. E uma minoria respondeu que não é preciso saber nada para se tornar artista (3).

Quando a pergunta foi sobre o que uma pessoa deveria saber para se tornar cientista (Gráfico 5), as respostas foram mais diversificadas.

Gráfico 5 - Qualidades de uma pessoa para ser cientista

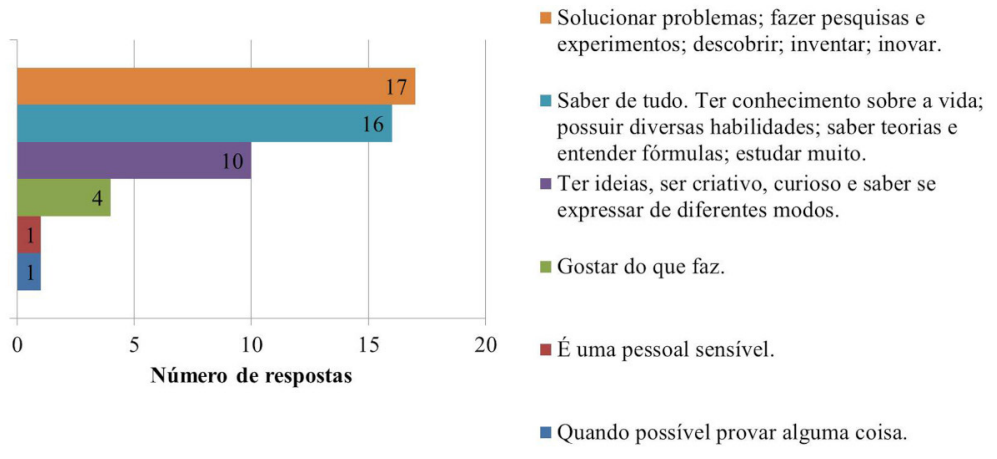

Fonte: elaborado pelos autores. 
Enquanto para os alunos o artista expressa seus sentimentos de maneira aparentemente "livre", considerando apenas seu ponto de vista sobre o mundo, para ser cientista, o caminho parece ser mais árduo na visão dos mesmos. Isso se evidencia no gráfico, ao observar que, em maior número, os alunos atribuíram muitas tarefas ao praticante da ciência, como: solucionar problemas, fazer pesquisas, experimentos, descobrir coisas (17), estudar muito e saber de tudo (16); ter ideias, ser criativo e se expressar de diferentes modos (10). Talvez pela forte exigência do trabalho científico, o mesmo deve "gostar do que faz" (4). Entretanto, um aluno escreveu que para ser cientista, também é preciso ser uma pessoa sensível (1). Considerou-se importante esse relato, pois demonstra uma imagem mais humanista da ciência, sobre a qual a prática científica é realizada para atender aos interesses sociais, o que exige uma sensibilidade apurada em relação ao objeto em estudo e os usos sociais da ciência (BOURDIEU, 2004). Por fim, um aluno manifestou o argumento de que a ciência deve "provar alguma coisa" (1).

A preocupação com a concepção dos alunos sobre a imagem do artista e do cientista, não tem o intuito de sobrepor uma a outra, mas sim oportunizar uma reflexão sobre o trabalho desses profissionais, que têm muito em comum nos percursos de criação e de descoberta, como também o consumo de suas produções pela sociedade.

A partir dos dados expressos nos Gráficos 4 e 5, pôde-se inferir que os alunos possuem uma visão estereotipada do artista e do cientista, permitindo associá-las a atividades sérias e não sérias. Por exemplo, a qualidade expressão e criatividade foi quantitativamente a mais associada ao artista. Porém, em relação ao cientista, essas mesmas qualidades só foram associadas por uma pequena parcela dos alunos (cerca de 20\%), o que indica que os alunos não associam a expressão - de sentimentos, ideias e criatividade -, como raciocínio e intelecção, evidenciando a concepção tradicional do ensino de arte e de ciências. Para eles, a arte "não é séria", é encarada como uma atividade desprovida de intelecção. Tanto que três alunos destacaram que "não é preciso saber nada para ser artista". Quanto ao cientista, este é "sério". Conforme podemos observar, os alunos destacaram o cientista pelo caráter pragmático das ciências, como se esse profissional exercesse seu ofício de forma linear e acumulativa, sem influências culturais.

O Gráfico 6 mostra se os discentes consideram a imagem importante para ciência.

Gráfico 6 - A importância da imagem para a ciência

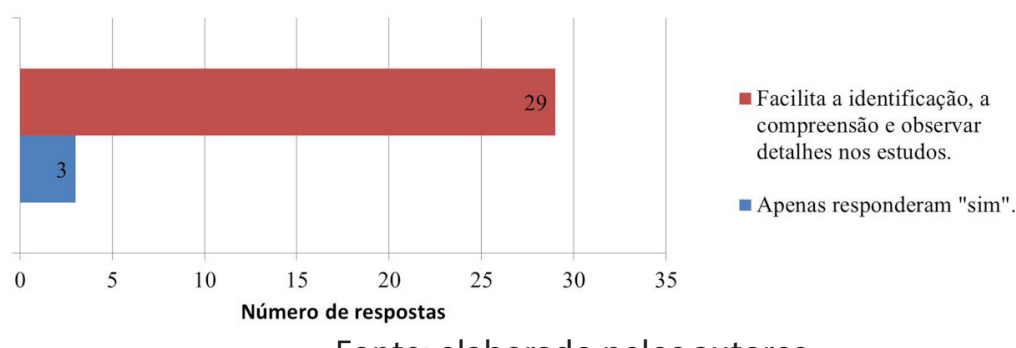

Fonte: elaborado pelos autores.

Pode-se afirmar que todos os alunos julgaram a imagem importante e necessária para a ciência, mesmo aqueles que limitaram suas respostas a apenas "sim". As justificativas apontaram que a imagem facilita o entendimento de determinados conteúdos e também oportuniza ver detalhes que não se podem enxergar a olho nu. 
Por fim, se no início da pesquisa os questionários trataram a arte e as ciências de forma separada, a última pergunta une essas duas áreas do conhecimento (Gráfico 7).

Gráfico 7 - A concepção dos alunos sobre a colaboração entre arte e ciências para a construção do conhecimento

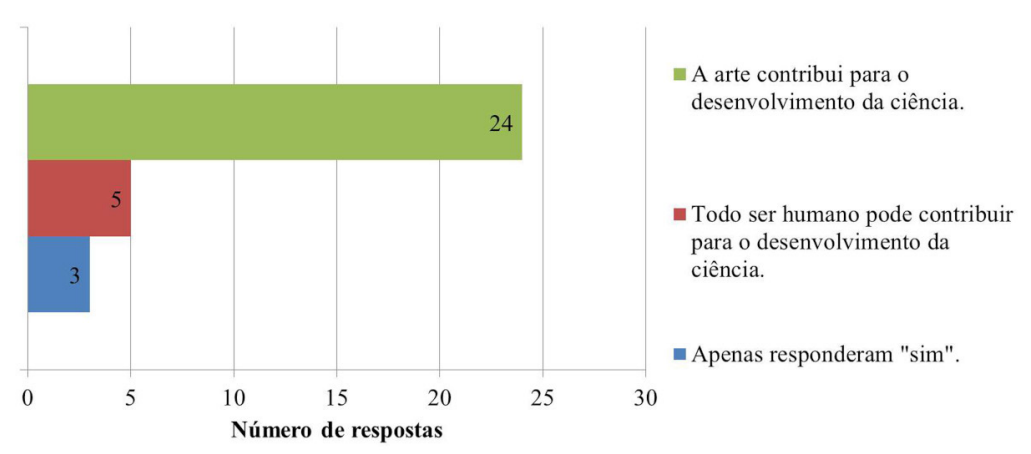

Fonte: elaborado pelos autores.

Em resposta se o artista ou o conhecimento artístico contribui para o desenvolvimento da ciência, os alunos revelaram que "sim" (24), como:

Resposta de aluno (grifo nosso): "Sim, pois tanto o cientista quanto o artista são inventores".

Também encontramos em três resposta o nome de Leonardo da Vinci.

Resposta de aluno (grifo nosso): "Sim, pois qualquer pessoa pode ser tanto pintor $e$ criador, como Leonardo da Vinci".

Resposta de aluno (grifo nosso): "Sim, pois muitos artistas sabiam fazer muito mais coisas como da Vinci que era inventor".

Resposta de aluno (grifo nosso): "Sim, como da Vinci, ele era pintor e inventor, construiu vários mecanismos que foram e ainda são uteis".

Contudo, nota-se que as respostas ainda se encontram superficiais, pois, como explicitado pelo Currículo do Estado de São Paulo, "[...] a beleza das ciências ainda é menos reconhecida que seu valor pragmático" (SÃO PAULO, 2010a, p. 26). Tanto que as palavras sublinhadas criador e inventor enfatizam a ideia de que o cientista deve apenas criar e inventar coisas e não oportunizar novas maneiras de interpretar os fenômenos, as causas naturais e suas implicações sociais.

Em cinco (5) respostas, os alunos apontaram que qualquer pessoa pode contribuir para a ciência.

Resposta de aluno (grifo nosso): "Sim, qualquer um pode criar uma coisa nova contribuindo para a ciência, não precisa ser pintor e desenhista".

A ideia de que a ciência deva ser aplicada persiste e, nas cinco respostas, os alunos apontaram que qualquer pessoa pode contribuir para ciência, desde que crie algo novo.

O argumento "qualquer pessoa pode contribuir para a ciência" merece ser mais discutido junto aos discentes, pois, em suas respostas, eles não mencionaram que fazemos ciência em boa parte de nossas tarefas diárias.

Conforme esclarece Arguello (1992), é necessário reconhecer que a ciência está presente em nosso dia a dia, desde a infância. Em nossos brinquedos, como por exemplo, nos aviões de papel, bicicletas etc. Ela também está presente em toda a nossa vida, quando interagimos com a natureza. 
Em outras três (3) respostas, os discentes simplesmente responderam, vagamente, "sim".

Diante do exposto, pode-se inferir que as relações entre arte e ciências, muito embora tenham sofrido alguma influência, não se modificaram significativamente. A interpretação que se faz é que a produção artística e científica independe do contexto em que são produzidas. Logo, pode-se reconhecer a necessidade da escola estabelecer os vínculos entre os conhecimentos artísticos e científicos e os modos de produção e aplicação desses conhecimentos na sociedade.

\section{Discussão dos Resultados}

A partir dos resultados apresentados, foi destacada, incialmente, a necessidade de formação e capacitação docente. Na entrevista o professor de ciências, este se refere à interdisciplinaridade como "uma época", transparecendo mais um modismo da educação brasileira do que de uma teoria da aprendizagem.

Do mesmo modo, o professor revelou que o tempo oportuno para se organizar e discutir propostas de trabalho que pudessem viabilizar "enfoques interdisciplinares" era limitado aos intervalos e às horas de atividades de trabalho pedagógico coletivo (ATPC).

Peloexposto, considera-se haverumabanalização da concepção de interdisciplinaridade, possivelmente ocasionada pela ausência do trabalho reflexivo e crítico (FAZENDA, 1994).

Quanto à associação da disciplina arte como uma atividade manual, cabe ressaltar que ela carrega, em sua trajetória, a defesa de sua obrigatoriedade na grade curricular, como a dispensa e a deturpação de propostas metodológicas, como aconteceu à chamada livreexpressão, que, pela falta de preparo, levou muitos profissionais a confundir improvisação com criatividade (BARBOSA, 2008). Na tentativa de driblar o espontaneísmo, Ana Mae Barbosa (BARBOSA, 2008, p. 21) propôs a abordagem triangular, que orienta o ensino de arte, mas alerta que "[...] aqueles que defendem a arte na escola meramente para liberar a emoção devem lembrar que podemos apreender muito pouco sobre nossas emoções se não formos capazes de refletir sobre elas".

Logo, um argumento a favor do ensino de arte na educação básica é que não se deve entender a cultura de um país sem conhecer sua arte, pois esta pode ser uma aguçadora de sentidos, já que transmite significados que não podem ser vistos por outras linguagens, daí a necessidade da alfabetização visual e da confirmação do papel da arte na escola (BARBOSA, 2008). Outro ponto reforçado por Barbosa (2008, p. 19) é que "[...] estamos rodeados por imagens veiculadas pela mídia, vendendo produtos, ideias, conceitos, comportamentos, slogans políticos etc. Como resultado de nossa incapacidade de ler imagens, nós aprendemos por meio delas inconscientemente".

Sendo assim, a alfabetização artística torna-se necessária, pois é conhecendo a sintaxe das linguagens artísticas que se aprende a ler e a interpretar as produções artísticas (BARBOSA, 2008), assim como tudo que nos é oferecido em termos visuais. Para Hernández (2000), o professor não deve considerar as obras de arte como objetos legítimos que nunca podem ter sua validade questionada. Defende que não apenas as imagens de obras de arte sejam utilizadas, mas também aquilo que se propaga no cotidiano, como um outdoor, uma capa de revista etc. Acredita que assim os alunos são incentivados a assumir uma postura crítica em relação aos sistemas de cultura. 
A alfabetização científica demanda um "[...] domínio conceitual científico básico, mesmo em se tratando de informações usuais presentes em jornais diários, equipamentos domésticos e embalagens de alimentos" (SÃO PAULO, 2010a, p. 35).

A interdisciplinaridade pode desconstruir os estereótipos reducionistas propagados pela cultura visual. Exemplo disso são imagens de cientistas que não correspondem ao que eles realmente fazem, estando sua aparência quase sempre associada a alguém vestindo um jaleco branco e manipulando aparelhos de laboratório (POZO; CRESPO, 2009). E a do artista, descrita por um aluno no questionário, de maneira precária, como uma atividade espontânea e livre de sentido, como a de um "macaco artista" apresentado pela telenovela Caras \& Bocas, entre 13 de abril de 2009 a 8 de janeiro de 2010, na Rede Globo de Televisão. Também não se deve desconsiderar que a mídia faz parte de nosso arcabouço cultural. Talvez para amenizar os estereótipos apresentados pelos meios de comunicação, seja necessário um relacionamento mais próximo entre os produtores da ciência e seus divulgadores.

É preciso considerar também que a restrição da educação a uma classe favorecida, por vezes acabou por impor às classes populares uma cultura dominante, que, a partir de muitos embates ao acesso à educação escolar, divide o mesmo espaço com a cultura popular, ou, em outras palavras, com o repertório cultural que o aluno já possui ao adentrar a educação básica, já que a escola tem por finalidade, de acordo com Currículo do Estado de São Paulo (SÃO PAULO, 2010b), alfabetizar o aluno nas diferentes áreas do conhecimento e Ihe oportunizar acesso a diferentes modalidades de expressão artística e produção cultural. Por isso, segundo Pozo e Crespo (2009, p. 23), as disciplinas que fazem parte do currículo devem permitir aos alunos incorporarem a cultura por eles vivida, em um sentido amplo, "[...] compartilhando as produções artísticas, científicas, técnicas, etc."

Quanto à produção, a concepção de "dons" associados ao fazer arte e ciência, Barbosa (2008) reflete que certas habilidades não são inatas ao ser humano, mas sim uma questão de "dão", ou seja, de oportunizar práticas e acesso ao conhecimento.

\section{Considerações Finais}

Diante da complexidade da pesquisa em elencar, analisar e apresentar as concepções do professor ciências e dos alunos sobre as relações entre arte e ciências na educação básica, neste momento chega-se não a uma única conclusão, e sim, a uma série de outros questionamentos.

Entende-se que a concepção de arte e de ciências, como conhecimentos polares, é influenciada pelo contexto ou pelo acesso dos discentes aos bens culturais, pois, em muitas de suas justificativas, as visões que possuíam do artista e do cientista estavam associadas aos estereótipos da imagem desses profissionais disseminadas pelos meios de comunicação e talvez até reforçada pela postura da escola, pois, em alguns momentos, a concepção do professor de ciências foi semelhante às concepções dos alunos. O artista é o homem louco que expressa suas emoções e sentimentos jogando tinta sobre a tela; já o cientista é um homem muito inteligente e mora em um laboratório. Logo, esse argumento denota a necessidade de o professor procurar descontruir essas concepções, posto que elas generalizam e depreciam a produção artística e a científica. 
Por isso, defende-se a necessidade de um pensamento crítico sobre as produções artísticas e científicas apresentadas pelos meios de comunicação, como também pelos materiais didáticos quanto aos seus impactos e consequências, procurando sempre recorrer a mais de uma fonte de informação, pois o que se é esperado é que o discente não tenha uma resposta única e objetiva aos problemas que se colocam em pauta, mas que possa equacionar e ter uma visão mais ampla do meio em que está inserido.

A alfabetização científica e artística pode contribuir para superar as "crises" do conhecimento fragmentado e superficial, como da concepção de "verdade" e "realidade" impregnadas na ciência e na imagem. Logo, a escola não deve assumir apenas a postura de construir o conhecimento, mas também de desconstruí-lo, posto que os alunos trazem conhecimento e cultura ao entrarem para ela. Essa desconstrução é a superação das concepções reducionistas contidas em certos hábitos e valores culturais, muitas vezes difundidos pela sociedade.

Por fim, reforça-se que é preciso entender as relações entre arte e ciências, pois essas duas áreas do conhecimento estão interligadas como se fossem metabioses da produção e expressão da humanidade, na qual o percurso investigativo, inventivo e criativo - que corresponde ao fazer artístico -, também desvela na produção científica. Essas devem ser reveladas e valorizadas na educação básica e compreendidas como dimensões culturais da humanidade. Tal como afirma Snow (2015, p. 72): "[...] fechar o fosso entre nossas duas culturas é uma necessidade tanto no sentido intelectual mais abstrato quanto no sentido mais prático. Quando esses dois sentidos se desenvolvem separados, nenhuma sociedade é capaz de pensar com sabedoria". Sendo assim, é preciso superar as barreiras do conhecimento unicamente especializado e construir pontes que nos permitam o acesso ao conhecimento nas mais diversas dimensões.

\section{Referências}

ALVES, Z. M. M. B.; SILVA, M. H. G. F. D. Análise qualitativa de dados de entrevista: uma proposta. Paidéia, Ribeirão Preto, n. 2, p. 61-69, 1992. DOI: http://dx.doi.org/10.1590/S0103$863 \times 1992000200007$.

ATALAY, B. A matemática e a Mona Lisa: a confluência da arte com a ciência. 2. ed. São Paulo: Publicações Mercuryo Novo Tempo, 2009.

ARGUELLO, C. A. O ensino de ciências: a responsabilidade curricular. Curitiba: SEED, 1992.

BARBOSA, A. M. Era uma vez... a obrigatoriedade das artes no currículo do ensino médio. Select, São Paulo, n. 33, p. 40-41, 2016. Disponível em: https://www.select.art.br/era-uma-vez-obrigatoriedadedas-artes-no-curriculo-do-ensino-medio/. Acesso em: 10 set. 2020.

BARBOSA, A. M. (org.). Inquietações e mudanças no ensino da arte. 4. ed. São Paulo: Cortez, 2008.

BARDIN, L. Análise de conteúdo. São Paulo: Edições 70, 1977.

BENEDICTO, E. C. P. Ciências e arte: entre conceitos, relações e implicações educacionais. 2018. 292 f. Tese (Doutorado em Educação para a Ciência) - Faculdade de Ciências, Universidade Estadual Paulista, Bauru, 2018. Disponível em: https://repositorio.unesp.br/handle/11449/180517. Acesso em: 10 set. 2020.

BOURDIEU, P. Os usos sociais da ciência: por uma sociologia clínica do campo científico. São Paulo: Ed. da UNESP, 2004. 
FAZENDA, I. Interdisciplinaridade: história, teoria e pesquisa. Campinas: Papirus, 1994.

FERNANDES JUNIOR, M. A. J. A fotografia como ferramenta interdisciplinar para o ensino de arte e ciências. 2017. 135 f. Dissertação (Mestrado em Docência para Educação Básica) - Faculdade de Ciências, Universidade Estadual Paulista, Bauru, 2017. Disponível em: https://repositorio.unesp.br/ handle/11449/150456. Acesso em: 10 set. 2020.

FREIRE, P. Pedagogia da autonomia: saberes necessários à prática educativa. São Paulo: Paz e Terra, 1996.

HERNÁNDEZ, F. Cultura visual: mudança educativa e projeto de trabalho. Porto Alegre: Artmed, 2000.

KUHN, T. S. A estrutura das revoluções científicas. 11. ed. São Paulo: Perspectiva, 2011.

LUCISANO, F. R.; NEVES, M. C. D. Uma análise das perspectivas inter e transdisciplinares na história da ciência presentes nos livros didáticos de física. In: SILVA, J. A. P. (org.). Arte e ciência: um encontro interdisciplinar. Maringá: Massoni, 2010. p.123-137.

PILLAR, A. D. A educação do olhar no ensino das artes. Porto alegre: Mediação, 2011.

POZO, J. I.; CRESPO, M. A. G. Aprendizagem e o ensino de ciências: do conhecimento cotidiano ao conhecimento científico. 5. ed. Porto Alegre: Artmed, 2009.

SÃO PAULO (Estado). Secretaria da Educação. Currículo do estado de São Paulo: ciências da natureza e suas tecnologias. São Paulo: SEE, 2010a.

SÃO PAULO (Estado). Secretaria da Educação. Currículo do estado de São Paulo: linguagens, códigos e suas tecnologias. São Paulo: SEE, 2010b.

SÃO PAULO (Estado). Secretaria da Educação. Material de apoio ao currículo do estado de São Paulo: caderno do professor; ciências, ensino fundamental - anos finais, $8^{a}$ série/ $9^{\circ}$ ano. São Paulo: SEE, 2014.

SILVA, J. A. P.; NEVES, M. C. D. O códex Cigoli-Galileo: ciência, arte e religião num enigma copernicano. Maringá: Eduem, 2015.

SNOW, C. P. As duas culturas e uma segunda leitura. São Paulo: Edusp, 2015. 